\title{
Submergence Tolerant Rice: SUB1's Journey from Landrace to Modern Cultivar
}

\author{
Julia Bailey-Serres • Takeshi Fukao • Pamela Ronald • \\ Abdelbagi Ismail $\cdot$ Sigrid Heuer $\cdot$ David Mackill
}

Received: 3 June 2010 / Accepted: 7 June 2010 /Published online: 4 August 2010

(C) The Author(s) 2010. This article is published with open access at Springerlink.com

\begin{abstract}
Rice landraces tolerant of up to 2 weeks of complete submergence were collected from farmers' fields in the 1950s. Success in fine mapping of SUBMERGENCE 1 (SUB1), a robust quantitative trait locus from the submergence tolerant FR13A landrace, has enabled marker-assisted breeding of high-yielding rice capable of enduring transient complete submergence. At the molecular level, SUB1 is a variable polygenic locus encoding two or three ethylene responsive factor (ERF) DNA binding proteins. All Oryza sativa accessions encode $S U B 1 B$ and $S U B 1 C$ at this locus. An additional ERF, $S U B 1 A$, is present at $S U B 1$ in FR13A and other tolerant accessions. The induction of SUB1A expression by ethylene during submergence disrupts the elongation escape strategy typical of lowland and deepwater rice, by limiting ethylene-induced gibberellic acid-promoted elongation. Microarray and metabolite studies confirm that SUB1A orchestrates its effects on metabolism and growth in a submergence-dependent manner. Due to the conditional activity of SUB1A, new "Sub1" mega-varieties effectively provide submergence tolerance without apparent ill effect on development, productivity, or grain quality.
\end{abstract}

Keywords Ethylene responsive factor FR13A .

Gibberellic acid $\cdot$ Mega-variety $\cdot S U B 1 A$

J. Bailey-Serres $(\bowtie) \cdot$ T. Fukao

Center for Plant Cell Biology, University of California,

Riverside, CA 92521, USA

e-mail: serres@ucr.edu

P. Ronald

University of California,

Davis, CA 94710, USA

A. Ismail $\cdot$ S. Heuer $\cdot$ D. Mackill

International Rice Research Institute (IRRI),

DAPO Box 7777, Metro Manila, Philippines

\section{Introduction}

Present and anticipated global food demands necessitate a significant increase in crop productivity in marginal farmlands. These include areas where soils, temperature, and water control are sub-optimal. Fortunately, local rice landraces cherished by farmers include accessions adapted to extremes in water availability, including tolerance to progressive flooding or rapid submergence that can be the source of genetic variation to be used to improve the adaptability of rice to extreme environmental stresses such as submergence. Rainfed lowland and deepwater rice together account for approximately $33 \%$ of global rice farmlands (50 million hectares of the estimated 150 million hectares of rice fields worldwide in 2004-2006 (IRRI Social Statistics Database; Huke and Huke 1997); Fig. 1). About two thirds of the shallow and intermediate rainfed lowland rice lands are in India, Thailand, and Bangladesh; other countries with a high percentage of rainfed lowland rice farms include Nepal, Myanmar, Laos, and Cambodia. Lowland rice is typically cultivated in paddies of 5 to $25 \mathrm{~cm}$ of standing water, which are highly vulnerable to Monsoon flash floods of $50 \mathrm{~cm}$ or more that can rapidly and completely submerge plants (Fig. 2). Oftentimes, transient submergence is repeated or followed by a period of stagnant partial flooding. When partially or completely submerged, most rice varieties display a moderate capacity to elongate leaves and the portion of stems that are trapped underwater. This elongation growth leads to a spindly plant that easily lodges when floodwaters recede. If the flood is deep, underwater elongation growth can exhaust energy reserves, causing death within a matter of days.

By contrast to lowland rice grown in shallow paddies, four to nine million hectares are cultivated with deepwater and floating rice varieties that are adapted to areas where water depth exceeds $50 \mathrm{~cm}$ for prolonged periods (Catling 1992; Fig. 1). These landraces typically produce circa $1 \mathrm{t} \mathrm{ha}^{-1}$ grain 
Fig. 1 Distribution of rice grown in upland, irrigated, rainfed lowland, and deepwater environments. (a) Percentage of rice type categorized by environment planted by continent and (b) in individual countries relative to total land area planted with rice (150 million hectares). Rough grain yield values are averages per country. Data were obtained from the IRRI Social Statistics Database. The information was compiled for 2004-2006 from the FAO 2007 database for rice area Asian country yearbooks and Huke and Huke (1997).
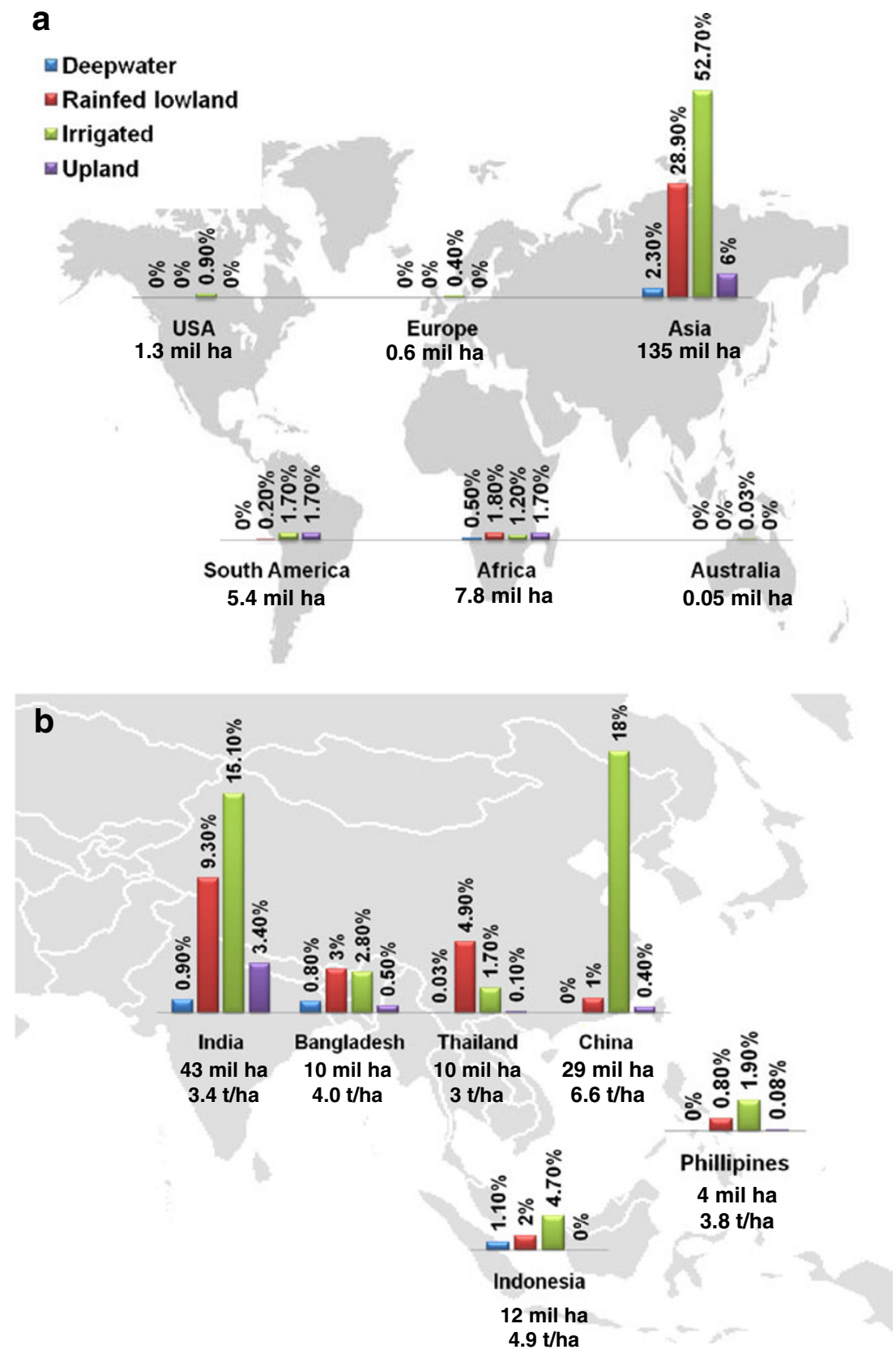

on highly elongated plants that thrive in paddies of up to $4 \mathrm{~m}$ in depth if the floodwaters rise progressively early in the growing season and leaves can be maintained above water (Catling 1992). Deepwater rice responds to partial submergence by enhancing cell division and elongation in the internodal regions of underwater stems, via a mechanism triggered by entrapment of ethylene, which promotes abscisic acid (ABA) degradation and increases gibberellic acids (GA) and their downstream effects (Kende et al. 1998; Hattori et al. 2009). Remarkably, stem elongation rates in deepwater varieties can reach $25 \mathrm{~cm} /$ day. This unusually robust underwater growth is controlled by three quantitative trait loci (QTLs). Of these, the SNORKEL QTL on chromo- some 12 encodes two ethylene responsive factor (ERF) DNA binding proteins, SNORKEL1 (SK1) and SNORKEL2 (SK2), that are absent from the non-deepwater rice accessions evaluated to date (Hattori et al. 2009). The underwater escape strategy of deepwater rice resembles that of semiaquatic plants that are adapted to environments that incur prolonged shallow floods. A pronounced strong elongation growth response of these wild species maintains sufficient aerial tissue above the air-water interface for efficient photosynthesis and oxygen exchange with submerged organs (Bailey-Serres and Voesenek 2008; Fig. 3).

Of the lowland rainfed rice farms worldwide, over 22 million hectares are vulnerable to flash flooding, represent- 


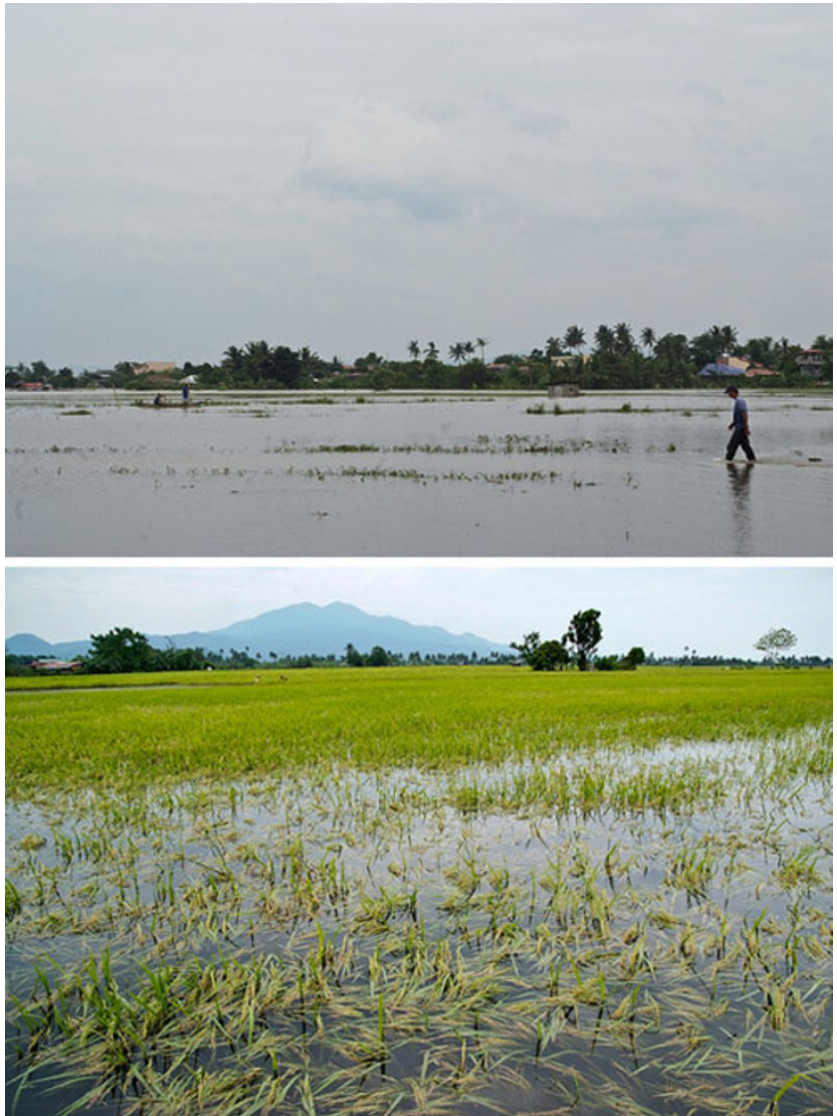

Fig. 2 Flooding of lowland rice paddies near Los Baños, Philippines, in September 2009. Photos courtesy of IRRI.

ing $18 \%$ of the global supply of rice (Khush 1984). An estimated ten million hectares in Bangladesh and India alone are marginalized by the threat of flooding each Monsoon season (Huke and Huke 1997). As a coping strategy, farmers have traditionally cultivated chronically flood-prone lowlands with landraces that can endure 10 days or more of complete submergence and resume growth upon de-submergence (Catling 1992). However, these submergence tolerant landraces produce less than $2 \mathrm{t}$ of grain ha ${ }^{-1}$, paling in comparison to the 6-8-t of grain $\mathrm{ha}^{-1}$ yields of advanced semi-dwarf varieties. Unfortunately, the popular "mega-varieties" grown in large areas of Asia are sensitive to complete submergence and usually die within 7 days of complete inundation. A challenge recognized by breeders in the 1970s was the need to improve yields in the rainfed lowlands by introduction of submergence tolerance to high yielding varieties (Mackill et al. 1996).

\section{Early breeding of submergence tolerant rice}

Landraces with unusual flooding and submergence tolerance were first reported in the early 1950s and systematically screened in the 1970s (Fig. 4). The accessions
FR13A and FR43B from Orissa, India and Kurkaruppan, Goda Heenati, and Thavalu from Sri Lanka were recognized for their resilience to complete submergence (Vergara and Mazaredo 1975; Mackill et al. 1996). FR13A stood out as extremely submergence tolerant; $100 \%$ of 10-day-old seedlings survived 7 days of complete submergence

\begin{tabular}{|c|c|c|c|}
\hline \multirow[t]{2}{*}{$\begin{array}{l}\text { Waterlogged } \\
\text { Lowland } \\
\text { Paddy }\end{array}$} & \multicolumn{2}{|c|}{ Completely Submerged } & $\begin{array}{c}\text { Partially } \\
\text { Submerged }\end{array}$ \\
\hline & $\begin{array}{c}\text { Submergence } \\
\text { tolerant } \\
\text { (Sub1) }\end{array}$ & $\begin{array}{l}\text { Lowland } \\
\text { submergence } \\
\text { intolerant }\end{array}$ & $\begin{array}{l}\text { Deepwater } \\
\text { rice }\end{array}$ \\
\hline $\begin{array}{l}\text { Waterlogged } \\
\text { paddy depth } \\
\text { (cm) }\end{array}$ & 5 to $<50$ & 5 to $<50$ & $>50$ to 400 \\
\hline Subspecies & $\begin{array}{c}\text { aus, } \\
\text { indica }\end{array}$ & $\begin{array}{l}\text { japonica, } \\
\text { indica }\end{array}$ & indica \\
\hline $\begin{array}{l}\text { Underwater } \\
\text { response } \\
\text { strategy }\end{array}$ & quiescence & escape & $\begin{array}{l}\text { deepwater } \\
\text { escape }\end{array}$ \\
\hline $\begin{array}{c}\text { Ethylene- } \\
\text { triggered GA- } \\
\text { mediated } \\
\text { elongation }\end{array}$ & suppressed & $\begin{array}{l}\text { enhanced in } \\
\text { shoot, leaf }\end{array}$ & $\begin{array}{l}\text { enhanced in } \\
\text { internodes }\end{array}$ \\
\hline $\begin{array}{c}\text { ERF } \\
\text { controlling } \\
\text { response } \\
\text { strategy }\end{array}$ & SUB1A & & SK1, SK2 \\
\hline
\end{tabular}

Fig. 3 Diversity in the response to partial to complete submergence in rice. Submergence tolerant rice, possessing the $S U B 1$ region from the landrace FR13A, limits underwater elongation growth via a quiescence strategy. SUB1A is the ethylene responsive factor (ERF) that controls this response. Submergence intolerant lowland rice lacks submergence-induced SUB1A and elongates when trapped underwater. The increase in growth to enable escape observed in these varieties resembles that of deepwater and floating rice. These types, however, have the capacity to dramatically extend internodes that are caught underwater as long as about $25 \%$ of the aerial tissue remains above water. The SNORKEL ERFs SK1 and SK2, present in deepwater and floating rice, contribute to the GA-mediated elongation growth that enables this remarkable extension of submerged shoots. The phytohormone ethylene triggers the expression of $S U B 1 A$ and the SNORKEL ERFs, although they drive antithetical growth responses. $S U B 1$ and SKs are members of the group VII ERF subfamily of transcription factors. 
Fig. 4 Sixty-year timeline of field, laboratory, and regulatory accomplishments that led to release of Sub1 mega-varieties with submergence tolerance in Asia.

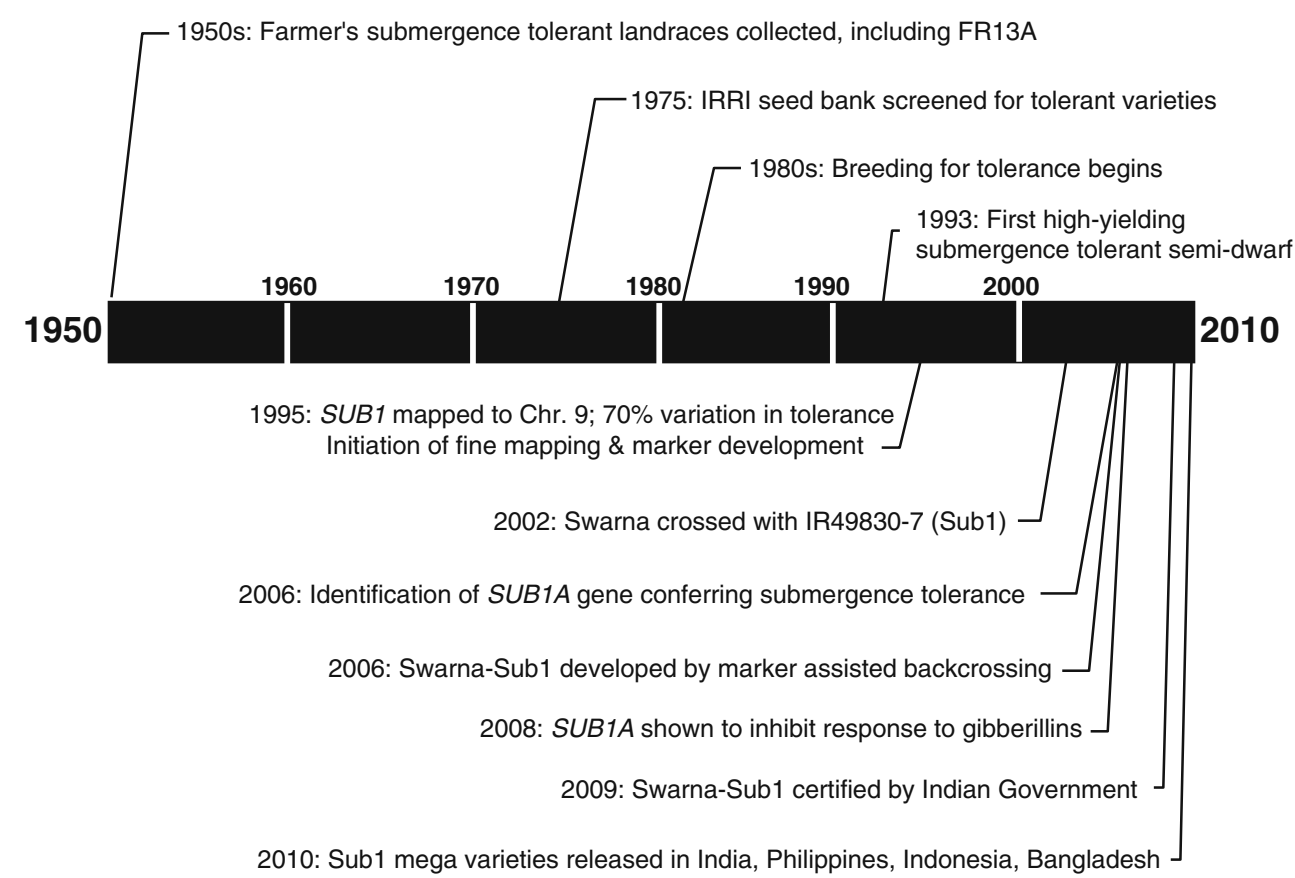

(Vergara and Mazaredo 1975; HilleRisLambers and Vergara 1982). However, FR13A lacks other agronomic attributes. It is photoperiod sensitive, tall, and provides low yields of poor-quality grain. Nonetheless, the recognition of landraces with pronounced submergence tolerance raised hopes that this trait could be introduced into advanced breeding lines to reduce yield loss from flash flooding. Although strides towards this goal began in the 1980s (Mohanty and Khush 1985; Mohanty and Chaudhary 1986; Haque et al. 1989), it was not until the mid-1990s that submergence tolerance from the FR13A-derived breeding line IR498307-1-2-2 was successfully introduced into productive short to intermediate stature lines (Mackill et al. 1993; Mishra et al. 1996). Fifty-day-old plants of these breeding populations showed prolonged submergence tolerance under greenhouse and field conditions.

\section{Mapping and molecular characterization of SUB1}

Until the mid-1990s, the genetic control of submergence tolerance remained ambiguous. Several studies suggested that it was a typical quantitative trait (Suprihatno and Coffman, 1981; Mohanty et al. 1981; Mohanty and Khush 1985; Haque et al. 1989). Molecular mapping allowed the identification of the major QTL SUBMERGENCE 1 (SUB1) on chromosome 9, contributing up to $70 \%$ of phenotypic variation in tolerance (Xu and Mackill 1996). Several independent studies confirmed the major chromosome 9 QTL and identified other minor QTLs that accounted for less than $30 \%$ of the phenotypic variation in tolerance (Nandi et al. 1997; Toojinda et al. 2003; Siangliw et al. 2003;
Fig. 5). SUB1 was further mapped with circa $3,000 \mathrm{~F}_{2}$ progeny to a $0.16-\mathrm{cM}$ region on chromosome 9 (Xu et al., 2000). This was followed by a fine-scale physical mapping study using 4,022 $\mathrm{F}_{2}$ individuals, narrowing the locus to $0.075 \mathrm{cM}$ (150 kb; six recombinants; Xu et al. 2006).

The positional cloning of $S U B 1$ was accomplished by identifying a contiguous set of BAC and binary clones spanning the region, using the intolerant indica Teqing and the tolerant FR13A derivative IR40931-26, respectively. This resolved a chromosomal integral, from marker CR25K to SSR1A that varies in length, structure, and gene content in the japonica and indica genomes, using Nipponbare and Teqing as representatives. The sequencing of the Teqing BAC contig in the $S U B 1$ region confirmed the presence of $\sim 50 \%$ interspersed sequences of transposon or retrotransposon origin (Xu et al. 2006). Recombination suppression in this region was associated with an inversion and large deletion, between markers 101O9L and 14A11-71K, in japonica relative to submergence intolerant Teqing and tolerant IR40931-26.

This variant segment of $S U B 1$ contains a gene designated $S U B 1 A$ that encodes a putative ERF DNA binding protein with a single ERF/APETELA2 domain (Xu et al. 2006; Fig. 5). Two additional ERFs, designated SUB1B and SUB1C, were identified proximal to the centromere within $\sim 100 \mathrm{bp}$ of $S U B 1 A$ in Teqing. The genome of the submergence intolerant japonica cultivar Nipponbare encodes $S U B 1 B$ and $S U B 1 C$ in this chromosomal interval but lacks SUB1A (GenBank AP006758 and AP005705). A survey of the ERF gene allele composition at the $S U B 1$ locus, or $S U B 1$ haplotype, of 21 rice accessions confirmed that all encode $S U B 1 B$ and $S U B 1 C$, but only a sub-set of indica and aus accessions encode $S U B 1 A$ 


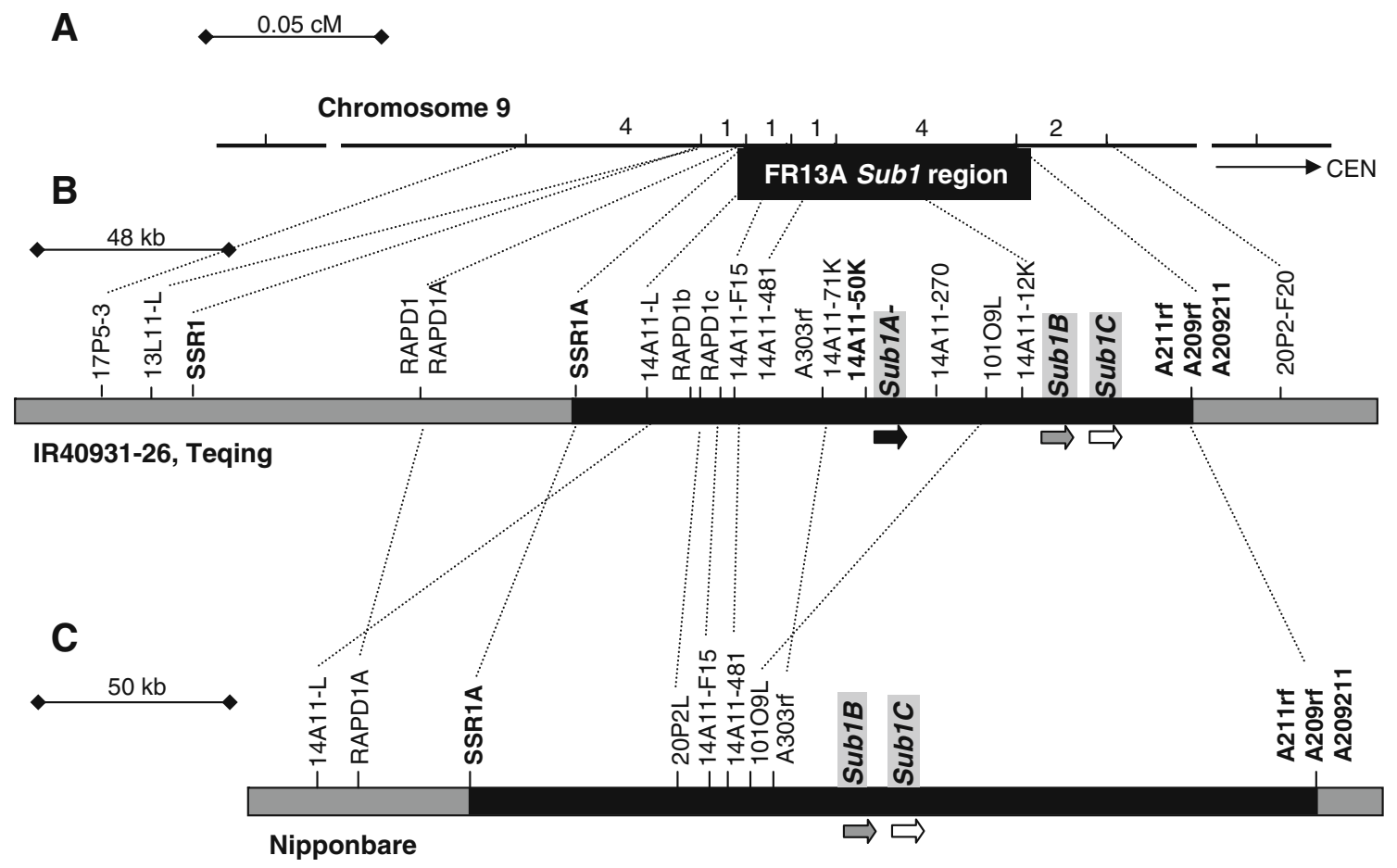

Fig. 5 Genetic and physical map of the SUBI locus on the long arm of chromosome 9. High-resolution maps represent FR13A derivative IR40931-26, Teqing (indica) and Nipponbare (japonica). The vertical lines indicate markers between maps. (a) The chromosomal segment defined by recombinant mapping as the SUB1 region, and its orientation relative to the centromere is indicated. Amplified fragment length polymorphism markers and their derivatives are prefixed with the letter " $A$." Genetic distances between adjacent markers are measured using the number of recombinant plants (one recombinant plant $=0.0012 \mathrm{cM}$ ). (b) Physical map spanning the SUB1 locus constructed by establishment and analysis of a BAC contig of six clones, including one from IRBB21 and five from Teqing, both intolerant indica. A contig of binary clones from IR40931-26, a

(Xu et al. 2006; Fig. 6). Phylogenetic analysis of the SUBI ERFs indicates that $S U B 1 A$ arose from a duplication of $S U B 1 B$, possibly after the domestication of indica rice (Fukao et al. 2009).

SUB1A is recognized in two allele forms in submergence tolerant and intolerant indica and aus accessions, based on nucleotide variations in the protein-coding region (Xu et al. 2006). SUBA1-1 is found only in tolerant lines such as FR13A, whereas the $S U B 1 A-2$ allele is present in intolerant indica accessions. SUB1A-1 and SUB1A-2 encode identical proteins, with the exception of $\operatorname{Ser}_{186}$ in the tolerant allele and $\mathrm{Pro}_{186}$ in the intolerant allele. Another distinction is recognized at the level of gene expression. SUB1A-1 promotes rapid, prolonged, and pronounced transcript accumulation in leaves of 14- to 28-day-old plants in response to submergence, whereas $S U B 1 A-2$ promotes a lower level of transcript induction by the stress (Fukao et al. 2006; $\mathrm{Xu}$ et al. 2006). Importantly, strong ectopic expression of the SUB1A-1 cDNA from FR13A in a highly submergence tolerant FR13A derivative, was also assembled across this region. The SUB1 locus was delimited to $42 \mathrm{~kb}$ between SSR1A and 14A11-481 and $112 \mathrm{~kb}$ between 14A11-f15 and AFLP209rf. Three group VII ERF genes are encoded in this region in IR04931-26 and Teqing, SUB1A, SUB1B, and SUB1C. IR40931-26 has the $S U B 1 A-1$ allele and Teqing the SUB1A-2 allele. (c) Physical map of the $S U B 1$ region in the Nipponbare genome. Based on DNA sequence data from GenBank, colinearity with the two physical maps (b, c) holds for most markers, SUB1B and SUB1C. However, there is an inversion and deletion of the region with the landmark marker 10109L and SUB1A. The sequenced SUB1 region in Nipponbare is $142 \mathrm{~kb}$. Adapted from Supplementary Fig. 1 of Xu et al. (2006). Photo by Pamela Ronald.

intolerant japonica proved to be sufficient to confer robust submergence tolerance (Xu et al. 2006).

An extensive analysis of diverse rice accessions with different $S U B 1$ haplotype showed that submergence tolerance is associated with variable levels of $S U B 1 A$ transcript in internodes and nodes at the heading stage (Singh et al. 2010). In Nipponbare transgenics expressing the GUS reporter gene under the control of the native SUB1A promoter, GUS activity was specifically induced by submergence in regions of leaves associated with growth, i.e., the leaf base and leaf collar, suggesting that SUB1A might act on the processes of cell division and/or cell elongation in leaves under submergence.

\section{Submergence stress and energy management}

Submergence imposes a complex abiotic stress (Setter et al. 1997; Jackson and Ram 2003; Sarkar et al. 2006; Bailey- 


\begin{tabular}{|c|c|c|c|c|}
\hline $\begin{array}{l}\text { Submergence } \\
\text { tolerant } \\
\text { (Sub1) }\end{array}$ & $\begin{array}{l}\text { aus } \\
\text { indica }\end{array}$ & $\bigsqcup_{\text {SUB1A-1 }} \operatorname{ser}_{186}$ & 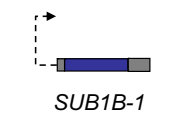 & SUB1C-1 \\
\hline \multirow{2}{*}{$\begin{array}{l}\text { Submergence } \\
\text { intolerant }\end{array}$} & indica & $\left.\right|_{-\underset{S U B 1 A-2}{\operatorname{Pro}_{186}}} ^{\rightarrow}$ & $\begin{array}{l}\rightarrow \\
\text { SUB1B-1,3,6,7 }\end{array}$ & $\bigsqcup_{\text {SUB1C-3,5,8 }}^{L_{\square}}$ \\
\hline & $\begin{array}{l}\text { indica } \\
\text { japonica } \\
\text { O. nivara } \\
\text { O. rufipogon }\end{array}$ & & $\begin{array}{l}- \\
\text { SUB1B-2,3,4,5,8 }\end{array}$ & $\bigsqcup_{\text {SUB1C-2,6 }}^{L_{\square}}$ \\
\hline
\end{tabular}

Fig. 6 Ethylene responsive factor (ERF) gene composition (haplotype) at the SUB1 locus of submergence tolerant and intolerant rice. Gene allele forms are indicated with a number following the gene name. Alleles are defined based on the nucleotide sequence encoding the ERF and not flanking or intervening sequences, which have additional polymorphisms (S. Heuer, personal communication). Japonica haplotypes lack SUB1A. Indica haplotypes are variable in allele composition and include accessions with or without a $S U B 1 A$ gene. The deepwater rice variety Pin Gaew 56 lacks SUB1A and displays a more pronounced increase in accumulation of transcripts encoding $S U B 1 B$ than $S U B 1 C$ (Fukao and Bailey-Serres, unpublished). The two alleles of $S U B 1 A$ have a single amino acid difference and are distinct in the level of transcript induction during submergence. Arrows above genes indicate transcript levels in leaves following submergence. Positions of introns are not shown. Oryza sativa data from $\mathrm{Xu}$ et al. (2006). Oryza nivara and Oryza rufipogon data from Fukao et al. (2009).

Serres and Voesenek 2008), and the extent of injury caused by complete submergence is largely dependent on floodwater conditions, particularly its temperature, turbidity, and the extent of light penetration (Das et al. 2009). The $10^{4}$-fold reduction in diffusion of gases in water relative to air limits the exchange of carbon dioxide and oxygen necessary for photosynthesis and respiration and increases the cellular concentration of the gaseous hormone ethylene. The reduction in light energy that reaches underwater leaves, especially in turbid waters, hastens chlorosis and leaf senescence (Ella et al. 2003). The stress can alter the availability and uptake of soil nutrients.

The major consequence of submergence is a reduction in photosynthesis and respiration. This is mitigated to some extent by thin gas films that form on the surface of submerged leaves, providing a microenvironment for efficient exchange of carbon dioxide and oxygen (Pedersen et al. 2009). However, complete submergence dramatically reduces the amount of oxygen that reaches roots via aerenchyma, limiting root development. Thus, an inevitable impact of submergence is a reduction in photosynthate and ATP production, limiting energy available for shoot and root growth. Despite this constraint, submergence intolerant cultivars typically accelerate the rate of stem and leaf elongation relative to non-submerged plants, which resembles the pronounced and effective internodal elongation of partially submerged deepwater rice. If the flood is deep, then elongating leaves may fail to reach the air-water interface before energy reserves are exhausted.

Through evaluation of near-isogenic lines differing only at the SUB1 locus, Fukao et al. (2006) demonstrated that genotypes lacking submergence-induced $S U B 1 A-1$ rapidly consume leaf starch and soluble sugars to maintain elongation growth during submergence. By contrast, genotypes with the SUB1 haplotype introgressed from FR13A consume carbohydrate energy reserves more slowly during submergence, maintaining growth at a rate similar to plants in air. When 14-day-old plants were submerged for 16 days, the viability of the SUB1 line (M202(SUB1)) was 98\%, whereas that of the non-tolerant japonica (M202) was $10 \%$. The low viability of M202 coincided with three times more shoot elongation. Findings with these near-isogenic lines were generally consistent with early studies that compared FR13A to unrelated submergence intolerant varieties. Overall, the submergence tolerance conferred by the SUB1 haplotype from FR13A is correlated with better maintenance of total soluble carbohydrates and limited elongation growth, lower aldehyde contents, less chlorophyll degradation, and less oxidative damage upon reoxygenation (Jackson and Ram 2003; Setter and Laureles 1996; Setter et al. 1997; Singh et al. 2001; Ella et al. 2003; Das et al. 2005; Fukao et al. 2006; Fukao and Bailey-Serres 2008). The finding of strong SUB1A-1 promoter activity in internodes and in the collar region and leaf base is consistent with a role in suppressing division and elongation of cells (Singh et al. 2010).

\section{Submergence tolerance provided by $S U B 1 A$-escape versus quiescence}

The distinction in submergence response strategy displayed by the landrace FR13A and deepwater rice illustrates a delicate balance between utilization versus conservation of reserves when overall energy production is compromised. In the case of a slow rising flood, investment of energy into elongation growth is a successful survival strategy. However, when the flood is deep and prolonged, the protection of energy reserves and growth meristems provides an advantage. Remarkably, the phytohormone ethylene and multigenic loci encoding ERFs control the distinct response strategies of submergence tolerant and deepwater rice. In both cases, the transcription of specific ERFs is promoted by submergence through the increase in cellular ethylene content in underwater organs (Fukao et al. 2006; Hattori et al. 2009; Fig. 3; Fig. 7).

Ethylene drives accumulation of SUB1A mRNA. The comparison of M202(SUB1) and M202 determined that ethylene evolution is significantly more pronounced in the submergence intolerant genotype M202 as compared to M202(SUB1), indicating that SUB1A directly or indirectly 
Escape

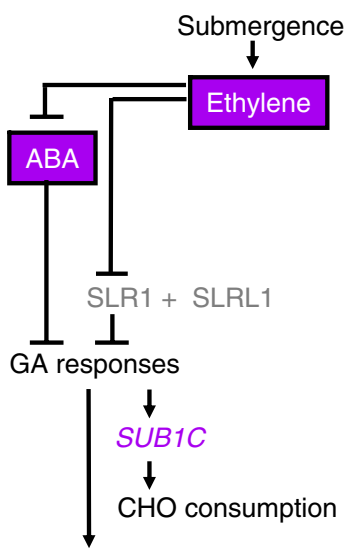

Elongation growth
Quiescence

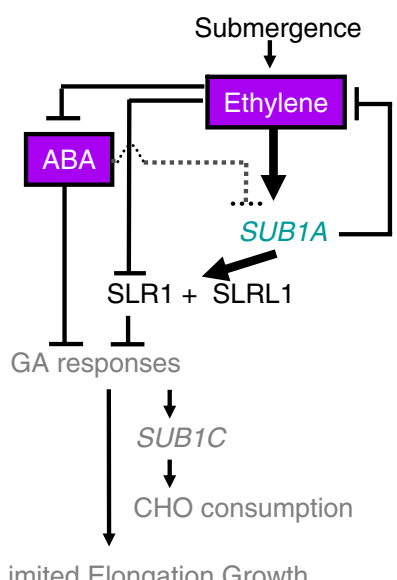

Limited Elongation Growth
Fig. 7 Lowland rice responds to partial to complete submergence by one of two strategies. The escape and quiescence strategies are controlled by distinctions in the ethylene responsive factors encoded by the SUB 1 locus. Quiescence requires strong induction of SUB1A by ethylene, which is increased as a consequence of submergence and biosynthesis. SUB1A is either poorly induced or absent in lowland rice varieties that attempt to escape submergence. The presence or absence of SUB1A does not affect the decline in ABA observed in response to submergence. In tolerant varieties, ethylene-promoted induction of SUB1A results in limited responsiveness to bioactive gibberellin (GA) because of increases in the GA response repressors SLR1 and SLRL1. The SUB1C gene, always present at the SUB1 locus, is triggered by de-repression of GA responsiveness. The underwater escape promoted by GA includes increased starch and soluble sugar catabolism and increased cell wall expansin proteins that promote expansibility (adapted from Fukao and Bailey-Serres 2008).

limits the further production of ethylene in submerged organs (Fukao and Bailey-Serres 2008). The increase in cellular ethylene levels also promotes accumulation of transcripts encoding ABA 8'-hydroxylases (ABA8ox), stimulating the catabolism of bioactive $\mathrm{ABA}$ to the unstable intermediate 8'-hydroxy ABA (Saika et al. 2007), which is spontaneously converted to phaseic acid (PA), and further reduced to inactive dihydrophaseic acid. Although ABA and PA levels decline to a similar extent in submerged leaves of both M202 and M202(SUB1), the presence of $S U B 1 A$ influences the downstream GA-mediated response.

More specifically, genotypes with $S U B 1 A-1$, i.e., M202 (SUB1) or transgenic japonica constitutively expressing SUB1A-1, restrict the decline in the GA signaling repressors SLENDER RICE 1 (SLR1) and SLR1-LIKE 1 (SLRL1) in submerged shoots (Fukao and Bailey-Serres 2008). SLR1 is a DELLA domain-containing transcription factor that is degraded by the $26 \mathrm{~S}$ proteasome in the presence of GA due to formation of a complex with GA and the GA-receptor. SLRL1 is a related protein that lacks the DELLA domain and is turned over by an unknown mechanism. The activation of SUB1A promotes both an increase in expression of SLR1 and SLRL1 mRNAs and maintenance of these proteins during submergence. Ethylene exposure is sufficient to promote the SUB1A-dependent elevation of SLR1 and SLRL1, resulting in a restriction in GA-induced elongation growth. By contrast, ethylene treatment promotes GA-induced elongation of shoots in M202. Consistent with these findings, downstream GA-induced responses are more evident in submergence intolerant accessions. These responses include elevation of $S U B 1 C$ as well as expansin, $\alpha$-amylase, and sucrose synthase mRNAs associated with cell wall loosening required for cell expansion, starch, and sucrose catabolism, respectively (Fukao et al. 2006; Fukao and Bailey-Serres 2008).

A recent transcriptome profiling study found that $S U B 1 A-1$ regulated levels of mRNAs encoding proteins associated with ethylene responses, GA biosynthesis, and cytokininmediated processes (Jung et al. 2010). The presence of SUB1A-1 also markedly affected submergence-regulated levels of mRNAs encoding transcription factors, with 16 of the 36 upregulated mRNAs encoding members of the ERF superfamily (i.e., ERF groups IIc, VII, and VIIIa). Future molecular characterization of the AP2/ERFs, which act downstream of SUB1A-1, should provide an understanding of the network of transcription factors that influences hormonal, metabolic, and developmental adjustments to submergence.

\section{Breeding of Sub1 mega-varieties}

Although complete submergence is a common natural disaster that damages rice production in many ricegrowing areas throughout the world, all commercially important cultivars are intolerant to the stress. The identification of the SUB1 QTL enabled its transfer by marker-assisted backcrossing (MABC) into the farmerpreferred varieties (Xu et al. 2004; Mackill 2006). The gene-level analyses of the $S U B 1$ region resolved single nucleotide polymorphisms within $S U B 1 A$ and $S U B 1 C$ that could be used for molecular markers and in precision breeding (Neeraja et al. 2007; Septiningsih et al. 2009). Using MABC, a small genomic region containing SUB1A has been introgressed into modern high-yielding varieties, such as Swarna, Samba Mahsuri, IR64, Thadokkam 1 (TDK1), CR1009, and BR11 (Septiningsih et al. 2009). Microsatellite markers that were polymorphic between the two parents were used to ensure that the recurrent parent genome was combined with the SUB1 region originally from FR13A on chromosome 9. Multiple evaluations of submergence tolerance in the greenhouse and farmers' fields confirmed that all "Sub1" lines exhibit significantly greater tolerance to complete submergence as compared with their original parents (Sarkar et al. 2009; Septiningsih et al. 2009; Singh et al. 2009; Fig. 8). 


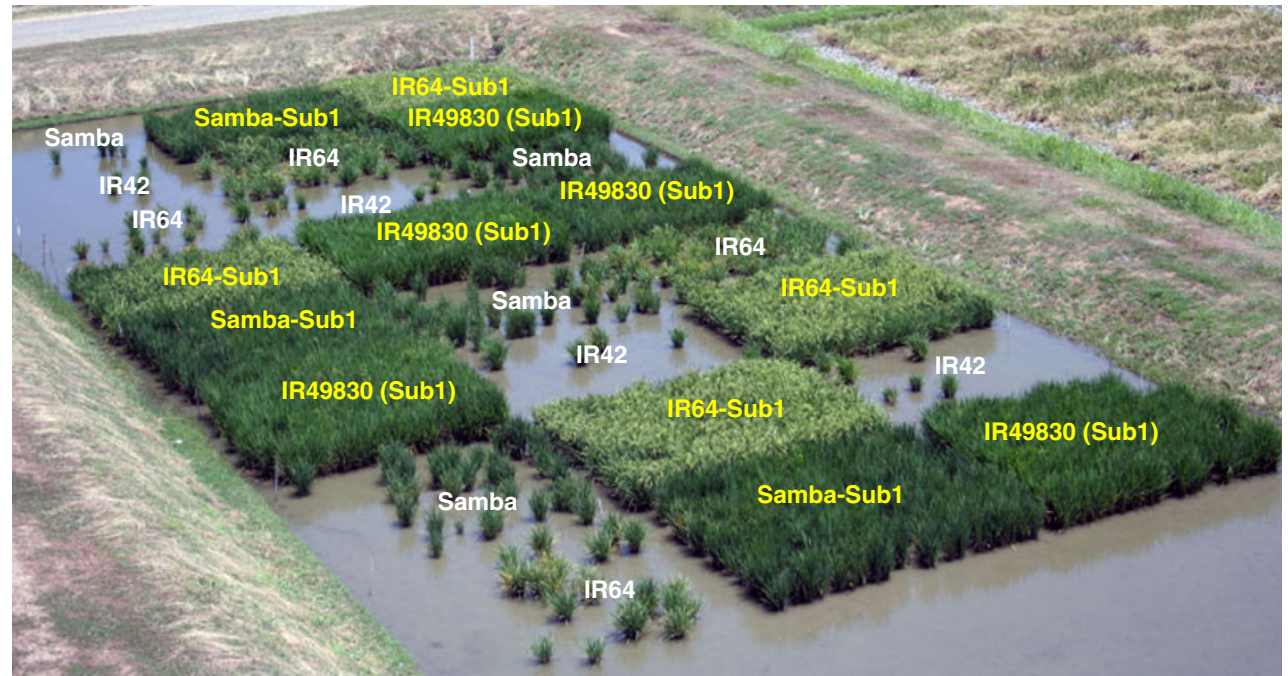

Fig. 8 Field plot test of submergence tolerance of Sub1 and non-Sub1 varieties. The $S U B 1$ locus from FR13A was introduced into the rice varieties IR64 and Samba Mahsuri by marker-assisted backcrossing and into IR49830-7-1-2-2 through conventional breeding. A field trial performed at IRRI in 2007 included Sub1 lines, the progenitors, and IR49830-7-1-2-2 (tolerant, used as SUB1 donor) and IR42 (sensitive)

These studies indicate that the introgression of the SUBI region of FR13A through MABC is widely applicable to diverse genetic backgrounds. In addition to submergence tolerance, the effect of SUB1 on growth, maturation, grain production, and grain quality was assessed in Swarna-Sub1, IR64-Sub1, and Samba Mahsuri-Sub1. Comparative analysis of the three Sub1 varieties and their original parents revealed that introgression of $S U B 1$ does not negatively affect agronomical performance including yield and grain quality under regular growth conditions (Sarkar et al. 2006, 2009; Neeraja et al. 2007; Singh et al. 2009). In intolerant varieties, complete inundation at the vegetative stage considerably decreases number of panicles, number of grains per panicle, and grain-filling percentage and delayed flowering and maturity, causing a dramatic decline in grain yield. Sub1 rice minimizes the reduction of these reproductive traits by a submergence event and produces three- to sixfold more grain by weight than the non-Sub1 varieties (Singh et al. 2009).

\section{Sub1 Rice in Farmers' Fields}

The major benefit of using the MABC approach is the resultant Sub1 varieties retain all the desirable features of the recurrent parent, especially the yield and quality characteristics. One explanation for the lack of adoption of previously developed Sub1 varieties such as IR49830-71-2-2 (Mackill 2006) was that genomic regions from the non-recurrent parent remained. Varieties with the SUB1 region from FR13A have the same yield, and other as checks. Fourteen-day-old seedlings were transplanted into a field with high levees, grown for 14 days and then completely submerged with about $1.25 \mathrm{~m}$ of water for 17 days. The field was drained, and the plants were allowed to recover under non-stress conditions. The photograph shows the performance of the lines about 60 days after de-submergence.

agronomic and grain quality characteristics as the original varieties when grown under shallow paddy conditions in the field; however, when subject to complete submergence for 7 to 15 days, these varieties showed considerable yield advantages (Singh et al. 2009; Sarkar et al. 2009). With the Sub1 mega-varieties, dissemination and adoption is more straightforward, because the main aim is the replacement of the original mega variety with an improved submergencetolerant version. The adoption of the Sub1 mega-varieties in non-flood-prone areas is likewise not a problem. Importantly, these introgression lines can also replace some of the low-yielding traditional landraces currently being used by farmers in submergence-prone areas, augmenting yields in typically marginalized fields.

Some of these tolerant lines were evaluated for their preferences and adoption by farmers in flood-prone areas in over ten countries in South and Southeast Asia over several years, in trials conducted in farmers' fields (Manzanilla et al. 2010, personal communication). Data from these trials demonstrated the consistent performance of these lines, validating the effectiveness of SUB1 in conferring tolerance of submergence, independent of the genetic background of the recipient variety or the environment where it is grown. The field performance of the new lines has encouraged many national rice improvement programs in Asia to commence rapid seed multiplication and dissemination schemes. For example, in 2009-2010, Swarna-Sub1 was released in India, Indonesia, and Bangladesh; BR11-Sub1 was released in Bangladesh; and IR64-Sub1 was released in the Philippines and Indonesia. Additional varieties are being introgressed 
with SUB1 at IRRI and by national breeding programs in several countries in Asia.

\section{Prospectus}

The marker-assisted introgression of the SUB1 region has successfully improved submergence tolerance in a wide range of mega-varieties without any penalties on development, yield, and grain quality (Sarkar et al. 2006, 2009; Neeraja et al. 2007; Singh et al. 2009). These new lines endure submergence, as long as the flood occurs after the seedling stage but before flowering and the flood completely subsides within 10 to 20 days, depending on floodwater conditions (Das et al. 2009). Although vegetative growth is restricted in some $S U B 1$ varieties until the water level drops to $10-15 \mathrm{~cm}$, mainly because of short stature, our recent studies showed that this is not the case when SUB1 is transferred into taller varieties or those with better tolerance of partial stagnant flooding $(20-50 \mathrm{~cm})$. The yield advantage provided by Sub1 introgression lines is anticipated to greatly stabilize production in rainfed lowland environments that experience flash flooding.

In contrast to Sub1 rice, deepwater rice escapes stagnant partial flooding by promoting elongation of internodes (Catling 1992; Hattori et al. 2009; Voesenek and BaileySerres 2009). Because the deepwater rice genes SK1/SK2 and the submergence tolerance gene SUB1A regulate ethylene-mediated GA responsiveness in an opposing manner, it seems unlikely that they can be combined to generate genotypes resilient of both stagnant flooding and submergence. However, greater understanding of the regulatory networks critical to balancing energy management and growth during submergence may identify natural genetic diversity in additional loci that can be used to improve the adaptability of rice to submergence. Along these lines, FR13A and other varieties have loci that map to regions other than SUB1 that improve submergence tolerance (Septiningsih et al. 2009; Singh et al. 2009). The reevaluation of QTLs from FR13A and moderately tolerant varieties lacking $S U B 1 A-1$ may enable further improvement of submergence tolerance.

The development of Sub1 rice largely spans the 50 years of pioneering research at the International Rice Research Institute (1960-2010). Further increase of rice production in marginal growing areas is needed. Targets that may aid in this objective include the generation of rice genotypes that combine submergence tolerance with tolerance of other abiotic and biotic stresses and grain quality attributes that match local consumers' preferences. For example, rice capable of germination and early coleoptile elongation in anaerobic soil has recently been identified and incorporated as a breeding target at IRRI (Ismail et al. 2009; Angaji et al.
2010; Ella et al. 2010) for direct seeding. This trait can be paired with $S U B 1$ if the two traits are expressed in specific developmental windows. In flood-prone tidal areas, farmers would benefit from rice that is tolerant of saline floodwaters, and in non-irrigated lowland areas that rely on natural rainfall for water, farmers will benefit from rice endowed with improved drought tolerance. The successful combination of submergence tolerance with other traits is likely to involve recognition of landraces with trait attributes that are unraveled at the genetic and molecular levels before their return to the farmer's field in improved varieties. Given the suite of postgenomic era tools and the breadth of the rice germplasm collection, these challenges will hopefully be accomplished with the haste needed to meet the world's food needs.

Acknowledgements Flooding research in the Bailey-Serres lab is supported by the National Institute of Food and Agriculture (200835100-04528) and the National Science Foundation (IOS-0750811). Research at IRRI was partially supported by the German Federal Ministry for Economic Cooperation and Development (BMZ), and the Bill and Melinda Gates Foundation.

Open Access This article is distributed under the terms of the Creative Commons Attribution Noncommercial License which permits any noncommercial use, distribution, and reproduction in any medium, provided the original author(s) and source are credited.

\section{References}

Angaji S, Septiningsih EM, Mackill DJ, Ismail AM. QTLs associated with tolerance of anaerobic conditions during germination in rice (Oryza sativa L.). Euphytica. 2010;172:159-68.

Bailey-Serres J, Voesenek LACJ. Flooding stress: acclimations and genetic diversity. Annu Rev Plant Biol. 2008;59:313-39.

Catling D. Rice in deep water. London: MacMillan Press Ltd.; 1992.

Das KK, Sarkar RK, Ismail AM. Elongation ability and non-structural carbohydrate levels in relation to submergence tolerance in rice. Plant Sci. 2005;168:131-136.

Das KK, Panda D, Sarkar RK, Reddy JN, Ismail AM. Submergence tolerance in relation to variable floodwater conditions in rice. Environ Exp Bot. 2009;66:425-34.

Ella E, Kawano N, Yamauchi Y, Tanaka K, Ismail AM. Blocking ethylene perception enhances flooding tolerance in rice seedlings. Funct Plant Biol. 2003;30:813-9.

Ella ES, Dionisio-Sese ML, Ismail AM. Proper management improves seedling survival and growth during early flooding in contrasting rice (Oryza sativa L.) genotypes. Crop Sci. 2010. doi:10.2135/ cropsci201.

Fukao T, Bailey-Serres J. Submergence tolerance conferred by Sub1A is mediated by SLR1 and SLRL1 restriction of gibberellin responses in rice. Proc Natl Acad Sci USA. 2008;105:16814-9.

Fukao T, Xu K, Ronald PC, Bailey-Serres J. A variable cluster of ethylene response factor-like genes regulates metabolic and developmental acclimation responses to submergence in rice. Plant Cell. 2006;18:2021-34.

Fukao T, Harris T, Bailey-Serres J. Evolutionary analysis of the Sub1 gene cluster that confers submergence tolerance to domesticated rice. Ann Bot. 2009;103:143-50.

Haque QA, Hille D, Lambers R, Tepora NM, Cruz QD. Inheritance of submergence tolerance in rice. Euphytica. 1989;41:247-51. 
Hattori Y, Nagai K, Furukawa S, Song XJ, Kawano R, Sakakibara H, et al. The ethylene response factors SNORKEL1 and SNORKEL2 allow rice to adapt to deep water. Nature. 2009;460:1026-30.

HilleRisLambers D, Vergara BS. Summary results of an international collaboration on screening methods for flood tolerance. Proceedings of the 1981 International Deepwater Rice Workshop. International Rice Research Institute, Los Baños, Philippines; 1982. p. 347-353.

Huke RE, Huke EH. Rice area by type of culture. South, Southeast, and East Asia. A revised and updated database. International Rice Research Institute, Los Baños, Philippines; 1997.

Ismail AM, Ella ES, Vergara GV, Mackill DJ. Mechanisms associated with tolerance to flooding during germination and early seedling growth in rice (Oryza sativa). Ann Bot. 2009;103:197-209.

Jackson MB, Ram PC. Physiological and molecular basis of susceptibility and tolerance of rice plants to complete submergence. Ann Bot. 2003;91:227-41.

Jung K-H, Seo Y-S, Walia H, Cao P, Amonpant F, Fukao T, et al. The submergence tolerance regulator SublA mediates stressresponsive expression of $\mathrm{AP} 2 / \mathrm{ERF}$ transcription factors. Plant Physiol. 2010;152:1674-92.

Kende H, van der Knaap E, Cho HT. Deepwater rice: a model plant to study stem elongation. Plant Physiol. 1998;118:1105-10.

Khush GS. Terminology of rice growing environments. Manila, Philippines: International Rice Research Institute; 1984. p. 5-10.

Mackill DJ. Breeding for resistance to abiotic stresses in rice: the value of quantitative trait loci. In: Lamkey KR, Lee M, editors. Plant breeding: the Arnel R Hallauer International Symposium. Ames: Blackwell Publishing; 2006. p. 201-12.

Mackill DJ, Amante MM, Vergara BS, Sarkarung S. Improved semidwarf rice lines with tolerance to submergence of seedlings. Crop Sci. 1993;33:749-75.

Mackill DJ, Coffman WR, Garrity DP. Rainfed lowland rice improvement. Los Banos, The Philippines: International Rice Research Institute; 1996.

Manzanilla DO, Paris TR, Vergara GV, Ismail AM, Pandey S, Labios RV, Tatlonghari GT, Acda RD, Chi TTN, Duoangsila K, Siliphouthone I, Manikmas MOA, Mackill DJ. Submergence risks and farmers' preferences: implications for breeding Sub1 rice in Southeast Asia 2010; (in press).

Mishra SB, Senadhira D, Manigbas NL. Genetics of submergence tolerance in rice (Oryza sativa L.). Field Crops Res. 1996;46:177-81.

Mohanty HK, Chaudhary RC. Breeding for submergence tolerance in rice in India. In: Progress in rainfed lowland rice. Manila: International Rice Research Institute, 1986;191-200.

Mohanty HK, Khush GS. Diallel analysis of submergence tolerance in rice, Oryza sativa L. Theor Appl Genet. 1985;70:467-73.

Mohanty HK, Suprihatno B, Khush GS, Coffman WR, Vergara BS. Inheritance of submergence tolerance in deepwater rice. Proceedings of the 1981 International Deepwater Rice Workshop. International Rice Research Institute, Los Baños, Philippines; 1982. p. 121-134.

Nandi SP, Subudhi K, Senadhira D, Manigbas NL, Sen-Mand S, Huang N. Mapping QTLs for submergence tolerance in rice by AFLP analysis and selective genotyping. Mol Gen Genet. 1997;255:1-8.

Neeraja C, Maghirang-Rodriguez R, Pamplona A, Heuer S, Collard B, Septiningsih E, et al. A marker-assisted backcross approach for developing submergence-tolerance rice cultivars. Theor Appl Genet. 2007;115:767-76.
Pedersen O, Rich SM, Colmer TD. Surviving floods: leaf gas films improve $\mathrm{O} 2$ and $\mathrm{CO} 2$ exchange, root aeration, and growth of completely submerged rice. Plant J. 2009;58:147-56.

Saika H, Okamoto M, Miyoshi K, Kushiro T, Shinoda S, Jikumaru Y, et al. Ethylene promotes submergence-induced expression of OsABA8oxl, a gene that encodes ABA 8'-hydroxylase in rice. Plant Cell Physiol. 2007;48:287-98.

Sarkar RK, Reddy JN, Sharma SG, Ismail AM. Physiological basis of submergence tolerance in rice and implications for crop improvement. Curr Sci. 2006;91:899-906.

Sarkar RK, Panda D, Reddy JN, Patnaik SSC, Mackill DJ, Ismail AM. Performance of submergence tolerant rice genotypes carrying the Sub1 QTL under stressed and non-stressed natural field conditions. Indian J Agric Sci. 2009;79:876-83.

Septiningsih EM, Pamplona AM, Sanchez DL, Neeraja CN, Vergara GV, Heuer S Ismail AM, Mackill DJ. Development of submergence tolerant rice cultivars: the Sub1 locus and beyond. Ann Bot. 2009; 103:151-160.

Setter TL, Laureles EV. The beneficial effect of reduced elongation growth on submergence tolerance of rice. J Exp Bot. 1996;47:1551-9.

Setter TL, Ellis M, Laureles EV, Ella ES, Senadhira D, Mishra SB, et al. Physiology and genetics of submergence tolerance in rice. Ann Bot. 1997;79(Suppl):67-77.

Siangliw M, Toojinda T, Tragoonrung S, Vanavichit A. Thai jasmine rice carrying QTLch9 (SubQTL) is submergence tolerant. Ann Bot. 2003;91:255-61.

Singh HP, Sing BB, Ram PC. Submergence tolerance of rainfed lowland rice: search for physiological marker traits. J Plant Physiol. 2001;158:883-9.

Singh S, Mackill DJ, Ismail AM. Responses of SUB1 rice introgression lines to submergence in the field: yield and grain quality. Field Crop Res. 2009;113:12-23.

Singh N, Dang T, Vergara G, Pandey D, Sanchez D, Neeraja C, Septiningsih E, Mendioro M, Tecson-Mendoza R, Ismal A, Mackill D, Heuer S. Molecular marker survey and expression analyses of the rice submergence-tolerance genes SUB1A and SUB1C. Theor Appl Genet. 2010. doi:10.1007/s00122-010-1400-z.

Suprihatno B, Coffman WR. Inheritance of submergence tolerance in rice (Oryza sativa L.). SABRAO J. 1981;13:98-102.

Toojinda T, Siangliw M, Tragoonrung S, Vanavichit A. Molecular genetics of submergence tolerance in rice: QTL analysis of key traits. Ann Bot. 2003;91:243-53.

Vergara BS, Mazaredo A. Screening for resistance to submergence under greenhouse conditions. In Proceedings International Seminar on Deepwater Rice. Dhaka, Bangladesh: Bangladesh Rice Research Institute; 1975. p. 67-70.

Voesenek LACJ, Bailey-Serres J. Genetics of high-rise rice. Nature. 2009;460:959-60.

$\mathrm{Xu} \mathrm{K}$, Mackill DJ. A major locus for submergence tolerance mapped on rice chromosome 9. Mol Breed. 1996;2:219-24.

$\mathrm{Xu} \mathrm{K,} \mathrm{Xu} \mathrm{X,} \mathrm{Ronald} \mathrm{PC,} \mathrm{Mackill} \mathrm{DJ.} \mathrm{A} \mathrm{high-resolution} \mathrm{linkage} \mathrm{map}$ in the vicinity of the rice submergence tolerance locus Sub1. Mol Gen Genet. 2000;263:681-9.

Xu KN, Deb R, Mackill DJ. A microsatellite marker and a codominant PCR-based marker for marker-assisted selection of submergence tolerance in rice. Crop Sci. 2004;44:248-53.

Xu K, Xu X, Fukao T, Canalas P, Maghirang-Rodriguez R, Heuer S, et al. Mackill, D.J. Sub1A is an ethylene responsive-factor-like gene that confers submergence tolerance to rice. Nature. 2006;442:705-8. 